death. These parameters had been defined by expert nominal group technique Methodologically, two main limitations had to be addressed: ${ }^{1}$ the problem of missing data and ${ }^{2}$ the low number of events, which prohibits the simultaneous exploration of a large set of predictors in a regression model. We addressed these issues by (a) imputing multiple predictors based on different algorithms (multiple imputation), and (b) using least absolute shrinkage and selection operator (LASSO) regression for 42 clinical parameters.

Results: Of 1451 patients who met the inclusion criteria, 706 had complete data available on all parameters for disease worsening. Of 706 patients originally evaluated, $228(32.3 \%)$ had disease progression, most of which was either a decrease in FVC (103 patients, 14.6\%) or death (92 patients, 13.0\%) within the observation period ( $12 \pm 3$ months). Of the 42 clinical parameters introduced into the model as outcome predictors, 8 remained in the final regression model, which was chosen by the Bayesian information criterion (table 1). Bootstrap with 10000 repetitions successfully validated the model.

\begin{tabular}{lccc}
\multicolumn{3}{l}{ Abstract FRI0456 - Table 1. Predictive factors in the final LASSO regression model } \\
\hline Factor & p-value & $\begin{array}{c}\text { Odds } \\
\text { ratio }\end{array}$ & $\begin{array}{c}95 \% \text { confidence } \\
\text { interval }\end{array}$ \\
\hline (Intercept) & $<0.0001$ & 0.06 & $0.03-0.14$ \\
Age (per 1 year) & 0.001 & 1.02 & $1.01-1.04$ \\
Active digital ulcers & 0.026 & 1.64 & $1.06-2.54$ \\
C-reactive protein & 0.002 & 1.80 & $1.23-2.63$ \\
elevation & & & \\
Significant dyspnoea & 0.491 & 1.20 & $0.72-2.00$ \\
Lung fibrosis & 0.0004 & 2.21 & $1.43-3.41$ \\
Muscle weakness & 0.015 & 1.64 & $1.10-2.45$ \\
Pericardial effusion & 0.098 & 1.65 & $0.91-2.97$ \\
Proteinuria & 0.064 & 1.75 & $0.97-3.16$ \\
\hline
\end{tabular}

Conclusions: The use of the predictive factors presented here could enable cohort enrichment with patients at risk for overall disease worsening in clinical trials.

Acknowledgements: This study was supported by Bayer AG (Berlin, Germany). Disclosure of Interest: M. Becker: None declared, N. Graf: None declared, R. Sauter: None declared, Y. Allanore Grant/research support from: Actelion Pharmaceuticals US, Bayer AG, Bristol-Myers Squibb, Inventiva, Medac, Pfizer Inc Roche Pharmaceuticals, Genentech and Biogen IDEC Inc. Sanofi-Aventis Pharmaceutical, Servier, Consultant for: Actelion Pharmaceuticals US, Bayer AG, Bris tol-Myers Squibb, Inventiva, Medac, Pfizer Inc, Roche Pharmaceuticals Genentech and Biogen IDEC Inc., Sanofi-Aventis Pharmaceutical, J. Curram Shareholder of: Bayer AG, Employee of: Bayer PIc, C. Denton Consultant for: Actelion Pharmaceuticals US, Bayer AG, GlaxoSmithKline, CSL Behring, Merck Serono, Roche Pharmaceuticals, Genentech and Biogen IDEC Inc., Inventiva Sanofi-Aventis Pharmaceutical, Boehringer Ingelheim, Speakers bureau: Actelion Pharmaceuticals US, Bayer AG, GlaxoSmithKline, CSL Behring, Merck-Serono, Roche Pharmaceuticals, Genentech and Biogen IDEC Inc., Inventiva, SanofiAventis Pharmaceutical, Boehringer Ingelheim, D. Khanna Shareholder of: Eicos Grant/research support from: Bayer, Bristol-Myers Squibb, Boehringer Ingelheim Genentech/Roche, NIH, Pfizer, Sanofi-Aventis Pharmaceuticals, Consultant for: Actelion Pharmaceuticals US, Bayer, Bristol-Myers Squibb, Boehringer Ingelheim, Chemomab, Corbus, Covis, Cytori, Eicos, EMD Serono, Genentech/Roche Pfizer, Gilead, GlaxoSmithKline, Sanofi-Aventis Pharmaceuticals, and UCB Pharma, M. Matucci-Cerinic Grant/research support from: Pfizer, Bristol-Myers Squibb, Actelion, UCB Pharma, Consultant for: Actelion, Bayer, ChemomAb, Genentech/Roche, Inventiva, Lilly, Pfizer, J. Pena Employee of: Bayer HealthCare Pharaceuticals Inc, J. Pope Grant/research support from: Actelion, Bayer AG, Bristol-Myers Squibb, Merck, Pfizer Inc, Roche, Consultant for: Actelion, Bayer AG, Bristol-Myers Squibb, Merck, Pfizer Inc, Roche, O. Distler Grant/ research support from: Actelion, Bayer, Biogen Idec, Boehringer Ingelheim, ChemomAb, EspeRare Foundation, Genentech/Roche, GlaxoSmithKline, Inventiva, Lilly, Medac, Medlmmune, Mitsubishi Tanabe Pharma, Pharmacyclics, Novartis Pfizer, Sanofi, Sinoxa, and UCB in the area of potential treatments of scleroderma and its complications. Patent mir-29 for the treatment of systemic sclerosis licensed, Consultant for: Actelion, Bayer, Biogen Idec, Boehringer Ingelheim, ChemomAb, EspeRare Foundation, Genentech/Roche, GlaxoSmithKline, Inventiva, Lilly, Medac, Medlmmune, Mitsubishi Tanabe Pharma, Pharmacyclics, Novartis, Pfizer, Sanofi, Sinoxa, and UCB in the area of potential treatments of scleroderma and its complications. Patent mir-29 for the treatment of systemic sclerosis licensed

DOI: 10.1136/annrheumdis-2018-eular.5296

\section{FRI0457 \\ RELATIONSHIP BETWEEN DIGITAL ULCERS AND SEVERITY OF LUNG FUNCTION TEST IN SYSTEMIC SCLEROSIS OVER A FIVE-YEAR PERIOD}

O.B. Ovsyannikova, O. Koneva, L. Ananieva. Department Of Vascular Pathology, Nasonova Research Institute of Rheumatology, Moscow, Russian Federation, Москва, Russian Federation

Background: Systemic sclerosis-related interstitial lung disease (SSc-ILD) is the leading cause of death in SSc. Predictors of the outcomes of ILD in SSc are under investigation.

Objectives: to assess association of the digital ulcers with dynamics of forced vital capacity (FVC) and diffusing capacity for carbon monoxide (DLco) in patients with SSc-ILD.

Methods: It was a longitudinal study involving 83 pts with SSc-ILD (mean age was $46,2 \pm 13,4 ; 69 \%$ have limited subset of the disease; $95 \%$ were female). The mean duration of follow up was $58,9 \pm 12,0$ months. At the end of the study a number of pts with digital ulcers (DUs) was 29 (35\%). Additionally 77 pts. with SSc-ILD were investigated with HRCT and were divided into 3 groups; The 1 st group (16 pts) with improvement; 2nd group (39 pts) without any changes and 3rd group (22 pts) with worsening of fibrosis.

Results: After 5 years of follow up FVC increased significantly in all pts without DUs $(n=54)$ from $88,5 \% \pm 19$ to $96 \% \pm 23(p<0,05)$; in group $1-$ from $92 \% \pm 20.5$ to $106 \% \pm 19(p<0,05)$; in group 2 from $87 \% \pm 18$ to $94 \% \pm 23.5(p<0,05)$ and only in group 3 FVC was stable $(88 \pm 22$ and $87 \pm 24.5)(p>0,05)$. The mean value of FVC in all pts with DUs didn't change $(88 \% \pm 14$ and $86 \% \pm 16, p>0,05)$ with tendency to decreasing in group 3 (from $83 \% \pm 12,5$ to $74 \% \pm 13$ ( $p>0,05$ ).

After 5 years of follow up DLco declined significantly in all pts with or without DUs, however in the 1 st group decline of DLco wasn't significant. The decreasing of DLCO was more prominent in group 3 than in group 2. Therefore, in group 2 in patient without DU $(n=24)$ - from $65 \% \pm 16$ to $60 \% \pm 11(p<0,05)$ and in patients with DU ( $n=14)$ DLCO changed from $61 \% \pm 15$ to $57 \% \pm 14(p<0,05)$. In 3rd group in patients without DU $(n=13)$ DLCO decreased from $55 \% \pm 15$ to $48 \% \pm 15(p<0,05)$ and in patients with DU ( $n=9)$ - from $50 \% \pm 20$ to $44,5 \% \pm 15(p<0,05)$.

Conclusions: In patients without DUs significant increasing of FVC during 5 years long follow up was observed. The worsening of fibrosis on HRCT in pts with DUs was associated with the lowest value of FVC and DLco at the entry and at the end of the study.

Disclosure of Interest: None declared

DOI: 10.1136/annrheumdis-2018-eular.4509

\section{FRI0458 \\ THE ONSET, CLINICAL COURSE AND OUTCOMES OF SSC- OVERLAP WITH PM/DM OR RA (SSC-PM/DM AND SSC-RA)}

O. Desinova, M. Starovoytova, L. Ananieva. VA Nasonova Research Institute of Rheumatology, Moscow, Russian Federation

Background: Systemic sclerosis (SSc) concurrent with other connective tissue diseases (poly/dermatomyositis, rheumatoid arthritis and oths) seem to be still underexplored clinical forms of SSc.

Objectives: To study specific features of the onset, clinical course and outcomes of systemic scleroderma- poly/dermatomyositis (SSc-PM/DM) and SSc-RA overlap syndromes.

Methods: Totally 115 patients were examined, 75 - with SSc-PM/DM and 40 with SSc-RA, among them 98 women and 17 men aged 17-74 years (mean age 44 $\pm 14,5$ ) and disease duration from 6 months to 35 years (median 8[2-8]).

Results: In $18 \%$ of overlapping SSc pts the disease manifested with isolated Raynaud's syndrome (RS) at the onset, in $61 \%$ - RS came in combination with cutaneous and/or joint and muscle pathology, and in remaining $7 \%$ and $2 \%$ overlapping SSc manifested with the isolated articular syndrome or muscular involvement (proximal weakness), respectively. During the first 3 years SSc generalisation with emerging signs of PM/DM occurred in $61 \%$ of patients, erosive arthritis manifested in $51 \%$; and in $20 \%$ of pts arthritis was detected later. Limited skin involvement predominated, while diffuse skin lesions were present in $23 \%$ of SSc-PM/DM cases, $1 / 3$ of them showed signs of DM. All pts with overlapping SSc syndrome received a glucocorticoids (GCs)-based combination therapy (SScPM/DM 30-60 mg/day, SSc-RA -10-20 mg/day), with NSAIDs and vascula drugs, $74 \%$ were administered cytotoxic agents, more often methotrexate $(48 \%)$ and $7 \%$ - antifibrotic drugs. Two types of overlapping SSc evolution patterns were identified: type I is favourable (stabilisation and slow progression without significant disease activity, and preserved work capacity); type II is unfavourable (continuing activity, rapid progression, disability and deaths). Favourable overlapping 
SSc pattern prevailed $(79 \%)$ in this study group, while unfavourable (21\%) mainly consisted of SSc-PM/DM cases. Favourable overlapping SSc evolution was observed in patients with the onset before the age of $40 \mathrm{y}$, while unfavourable course was documented in pts with the late SSc onset at $>40 \mathrm{y}$, with prevailing SSc-PM/DM. Fatal outcomes in $10 \%$ of cases mostly belong to SSc-PM/DM pts $(8 \%)$. The specific features of overlapping SSc evolution included augmentation of SSc-characteristic symptoms - both, peripheral - teleangiectasias, calcification, osteolysis and digital trophic lesions, mainly in SSc-PM/DM pts, and visceral - involving heart, lungs, and oesophagus, which determined the unfavourable prognosis. RA manifestations (articular syndrome) in overlapping SSc pts tended to decrease, while signs of PM tended to resolve.

Conclusions: Timely detection of overlapping SSc pathological symptoms with administration of adequate therapy and dynamic monitoring of patients will improve the prognosis and outcomes of the disease.

Disclosure of Interest: None declared

DOI: 10.1136/annrheumdis-2018-eular.5134

\section{FRI0459 MICROVACULATURE CHANGES AND ANGIOGENIC FACTORS IN SYSTEMIC SCLEROSIS - A SINGLE CENTRE STUDY}

R. Bečváŕr ,H. Hulejová ${ }^{2}$, I. Půtová ${ }^{2}$, M. Tomčík ${ }^{2} .{ }^{1}$ Department of Rheumatology ${ }^{2}$ Institute of Rheumatology, Praha 2, Czech Republic

Background: In systemic sclerosis (SSc) low capillary density in acral parts leads to a reduced blood flow, to tissue ischemia. Tissue hypoxia usually initiates the formation of new blood vessels from the pre-existing microvasculature. Despite the reduced blood flow and partial oxygen pressure levels, there is no evidence for a sufficient angiogenesis in the skin of patients with SSc. Nailfold capillaroscopy is a safe, noninvasive routine way for the microvascular investigation. At the same time different cytokines and angiogenic factors are produced.

Objectives: The aim of this study was to assess whether blood levels of angiogenic biomarkers are associated with microvasculature changes in SSc patients. Methods: Microvasculature changes were assessed using nailfold videocapilaroscopy (NVC) which was performed by two independent examiners. The obtained images were analysed anonymously by two investigators blinded for the clinical and serum status of SSc patients and classified as early, active and late pattern. ${ }^{1}$ Serum or plasma levels of soluble vascular adhesion molecule- 1 (sVCAM-1) and soluble intercellular adhesion molecule-1 (sICAM-1) were measured by ELISA, big endothelin-1 (BET-1) concentrations using competitive enzyme-immunoassay and von Willebrand factor antigen (vWFAg) concentrations using ELISA kit were measured. As potential disease activity markers soluble receptor of interleukin-2 (sIL-2r) and interleukin-6 (IL-6) serum levels using commercial kits were assayed. For statistical evaluation Pearson's correlation coefficient and univariate analysis were used.

Results: Total 40 patients ( 38 females) were investigated: 30 individuals with limited form, 5 with diffuse, 3 patients with scleroderma sine scleroderma, 1 with overlap syndrome and 1 with undifferentiated connective tissue disease. The mean age \pm standard deviation (SD) of the whole cohort was $51 \pm 22$ years and the mean disease duration \pm SD was $10 \pm 7$ years. 3 patients $(7.5 \%)$ had early NVC pattern, 12 patients $(30 \%)$ had active, $10(58 \%)$ late pattern, and $15(37.5 \%)$ had nonspecific changes or normal picture.

The patients with late NVC pattern exhibited higher vWFAg levels than patients with active pattern $(p<0.01)$. BET-1 and sICAM-1 serum levels were higher in the active pattern compared with late patterns $(p<0.01$ and $p<0.05$, respectively). When correlating these potential biomarkers with SSc-related clinical characteristics we found only these associations: vWFAg levels with heart arrhythmias and modified Rodnan skin score ( $p<0.01, p<0.05$, respectively).

Conclusions: VWFAg and ET-1 increase in the late NVC pattern can be considered as an attempt to support deficient vasculogenesis. Further studies are needed to determine the role of other potential biomarkers of endothelial injury and repair in SSC.

\section{REFERENCES:}

[1] Cutolo M, et al. Nailfold videocapillaroscopy assessment of microvascular damage in systemic sclerosis. J Rheumatol 2000;27:155-60.

[2] Hasegawa M. Biomarkers in systemic sclerosis: Their potential to predict clinical courses. J Dermat 2016:43:29-38.

Acknowledgements: This study was performed with support of $\mathrm{CMH}$ Research Projects No 00000023728 .

Disclosure of Interest: None declared

DOI: 10.1136/annrheumdis-2018-eular.5139

\section{FRI0460 \\ THE COMPARISON BETWEEN PATIENTS WITH SYSTEMIC SCLEROSIS, POSITIVE FOR FOR ANTIBODIES TO RIBONUCLEOPROTEIN AND CLASSICAL SUBTYPES OF SYSTEMIC SCLEROSIS}

R. Shayakhmetova ${ }^{1}$, L. Ananieva ${ }^{1}$, O. Koneva ${ }^{2}$, M. Starovoitova $^{2}$, O. Desinova ${ }^{2}$, O. Ovsyannikova ${ }^{2}$, L. Garzanova ${ }^{2} .{ }^{1}$ V.A. Nasonova Research Institute of Rheumatology, Moscow, Russian Federation; ${ }^{2}$ Kashirskoe Shosse 34A, V.a. nasonova Research Institute of Rheumatology, Moscow, Russian Federation

Background: Different clinical subtypes of systemic sclerosis (SSc) vary in frequency and severity of symptoms, progression of internal organ involvement and outcomes. The frequency of antibodies to ribonucleoprotein (RNP) in SSc varies from $5 \%$ to $30 \%$ according to reports of different studies and can be connected with separate clinical subtype of SSc.

Purpose: to characterise the main clinical features of patients with SSc positive for antibodies to RNP and to compare them with ACA and Scl-70 positive subtypes of SSc.

Objectives: to characterise the main clinical features of patients with SSc positive for antibodies to RNP and to compare them with ACA and Scl-70 positive subtypes of SSc.

Methods: The study included 330 patients (289 women and 41 men, mean age $50 \pm 13$ years) meeting the criteria of the SSc (ACR/EULAR 2013 observed between 2011 and 2017. The level of anti-nuclear antibodies was determined by ELISA. The normal level of antibodies to RNP (U1-RNP-70) was 0-25 U/ml. The level greater than 3 times the upper limit of normal considered as highly positive.

Results: In study group of 330 patients $49(15 \%)$ had antibodies to ACA, 154 (46\%) - to Scl-70, $67(20 \%)$ - to RNP antibodies. Also 4 patients simultaneously had antibodies to Scl-70 and RNP, 4 patients - to ACA and RNP, 1 patient to ACA, Scl-70 and RNP. Among RNP + group $85 \%$ of patients were highly positive and $15 \%$ - low-positive.

The vast majority of patients were female $(91 \%)$, mean age $44,2 \pm 15$ years. RNP +group was similar to ACA + group by predominance of a limited form of the dis ease which was $67,3 \%$ and $97 \%$ correspondingly. At the same time RNP +group was similar to Scl-70 +group by frequent involvement of internal organs - intestinal lung disease 67,3 and $69 \%$ correspondingly, involvement of cardiovascular system $-21 \%$ and $34 \%$, esophagitis $61 \%$ and $44,5 \%$.

RNP + group had scleredema frequently $-40 \%$, in comparison with ACA+ $(10 \%$ $\mathrm{p}<0,005)$ and $\mathrm{Scl}-70+(6,5 \%, \mathrm{p}<0,005)$, involvement of joints (arthralgia/arthritis) $65 \%$ in comparison with $\mathrm{ACA}+(24 \%, \mathrm{p}<0,005)$ and Scl-70+ $(24 \%, \mathrm{p}<0,005)$, muscle weakness/pain - $43 \%$, in comparison with ACA $+(0,2 \%, p<0,005)$ and $\mathrm{Scl}-70+(10,4 \%, \mathrm{p}<0,005)$. All 3 groups did not differ significantly by the presence of Raynauds syndrome, telangiectasia and vascular manifestations (fingertip pitting scars or digital tip ulcers).

Furthermore patients with SSc highly positive for antibodies to RNP, met the crite-

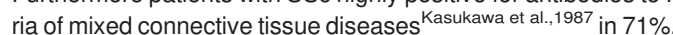

Conclusions: Our cogort of patients with SSc have high frequency of highly positive level of antibodies to RNP - 17\%. Combination of specific SSc anti-nuclear antibodies (ACA, Scl-70) and antibodies to RNP was uncommon $(2,7 \%)$ and predominantly in low-positive for antibodies to RNP patients.

The distinctive features of RNP + group in contrast to the "classical" subtypes of SSc were more mild skin involvement (puffy fingers) and more severe muscle and joints involvement.

Despite the limited form of the disease and mild skin involvement, RNP +group is more similar to Scl-70 + group by frequent involvement of internal organs.

We propose that well known relation between skin involvement in diffuse form of SSc with Scl-70 +and organ damage is not so evident in RNP + group of SSc.

Disclosure of Interest: None declared

DOI: 10.1136/annrheumdis-2018-eular.6631

\section{FRI046 \\ EFFICACY AND SAFETY OF ANTIFIBROTIC AGENTS IN IDIOPATHIC PULMONARY FIBROSIS}

L. Nuñez-García ${ }^{1}$, C. Valenzuela ${ }^{1}$, T. Alonso ${ }^{1}$,E.F. Vicente ${ }^{2}$,J. Ancochea ${ }^{1}$,

S. Castañeda ${ }^{2} .{ }^{1}$ Pneumology; ${ }^{2}$ Rheumatology, Hospital Princesa, Madrid, Spain

Background: Antifibrotic (AF) agents are a family of drugs that improve the survival and quality of life of patients with idiopathic pulmonary fibrosis (IPF). Given that pulmonary fibrosis is also a common manifestation of many autoimmune dis eases, we think of interest to know the efficacy and safety data of these agents in real life, which will likely soon reach the therapeutic arsenal of the rheumatologist. Objectives: To analyse the efficacy and safety of treatment with AF pirfenidone (Pi) and nintedanib (Ni) at one year in patients with mild-moderate IPF treated in our hospital according to clinical practice.

Methods: Retrospective observational study in which all patients diagnosed with mild-moderate IPF who started treatment with Pi and/or Ni between January 2012 and May 2017 in our Hospital were included. The response was evaluated according to the results obtained in the Respiratory Function Tests: forced vital capacity (FVC) and carbon monoxide diffusion test (DLCO), which were carried out every 3 